\section{World Day of Remembrance for Road Traffic Victims - November 20, 2016}

In October 2005, the General Assembly of the United Nations (UN) adopted a resolution calling for governments and nongovernmental organizations to mark the third Sunday in November each year as World Day of Remembrance for Road Traffic Victims. World Remembrance Day is dedicated to remembering persons killed or injured in road crashes and their families and communities. The day also pays tribute to the emergency crews, police and medical professionals who deal with the traumatic aftermath of road deaths and injuries (http://www.worlddayofremembrance.org).

Road traffic injuries are the ninth leading cause of death worldwide, and the leading cause of death among persons aged 15-29 years. Approximately 1.25 million persons die each year on the world's roads, and 20-50 million persons sustain nonfatal injuries (1). A recent CDC report comparing the United States with 19 other high-income countries determined that the United States had the highest number of motor vehicle crash deaths per 100,000 persons, and per 10,000 registered vehicles; the second highest percentage of deaths involving alcohol-impaired driving; and the third lowest use of front seat belts (2). During 2015, deaths from car crashes increased in the United States (3), and an increase is projected for the first half of 2016 (4). The U.S. Department of Transportation has joined with partners to launch the "Road to Zero" coalition, with the goal of ending U.S. traffic fatalities within 30 years (http://www.nhtsa.gov/About-NHTSA/ Press-Releases/nhtsa_zero_deaths_coalition_10052016). Implementing proven effective strategies to prevent road traffic fatalities can save thousands of lives and hundreds of millions of dollars in the United States (2).
CDC supports UN and World Health Organization (WHO) measures to dedicate 2011-2020 as the Decade of Action for Road Safety. The Decade of Action for Road Safety was launched in May 2011 in more than 100 countries, with the goal of preventing 5 million road traffic deaths globally by 2020 . The UN is also committed to measures to reduce the number of global road traffic deaths and injuries by half by 2020 as part of the UN's Sustainable Development Goals (http://www.un.org/ sustainabledevelopment/sustainable-development-goals/).

Organizations interested in action strategies to support victims and survivors (5) can find materials and additional information about the World Day of Remembrance at http:// www.worlddayofremembrance.org.

\section{References}

1. World Health Organization. Global status report on road safety 2015. Geneva, Switzerland: World Health Organization; 2015. http://www. who.int/violence_injury_prevention/road_safety_status/2015/en/

2. Sauber-Schatz EK, Ederer DJ, Dellinger AM, Baldwin GT. Vital signs: motor vehicle injury prevention-United States and 19 comparison countries. MMWR Morb Mortal Wkly Rep 2016;65:672-7. http:// dx.doi.org/10.15585/mmwr.mm6526e1

3. National Center for Statistics and Analysis. 2015 motor vehicle crashes: overview. Washington, DC: US Department of Transportation, National Highway Traffic Safety Administration, National Center for Statistics and Analysis; 2016. https://crashstats.nhtsa.dot.gov/Api/Public/ ViewPublication/812318

4. National Center for Statistics and Analysis. Early estimates of road traffic fatalities for the first half (Jan-Jun) of 2016. Washington, DC: US Department of Transportation, National Highway Traffic Safety Administration, National Center for Statistics and Analysis; 2016. https:// crashstats.nhtsa.dot.gov/Api/Public/ViewPublication/812332

5. World Health Organization; Global Alliance of NGOs. Advocating for road safety and road traffic injury victims: a guide for nongovernmental organizations. Geneva, Switzerland: World Health Organization; 2012. http://www.who.int/violence_injury_prevention/publications/road_ traffic/ngo_guide/en/ 